intrepid traveller. Mr. Stanley is bent on calling the great river, so much of which he has explored, by the name of Livingstone. As a rule we think it a mistake to change native geographical names where these can be satisfactorily ascertained. In the case of the LualabaCongo, however, the river seems to have quite as many names as there are tribes or villages on its banks, and it would be a happy solution of the difficulty to confer upon it the most memorable name among African explorers. Mr. Stanley himself has taken great pains to obtain accurately the native names of tribes and places, and he animadverts with severity on geographers for crowding the map of Africa with names that probably correspond to nothing. For this they cannot be greatly blamed, neither need he be too hard on previous travellers for misunderstanding the significance of native words.

A glance at the map, notwithstanding that it is based to some extent on conjecture, shows at once the vast importance of Mr. Stanley's discovery. Great tributaries join the main river from both sides, and we are assured there are many more besides these shown on the map. For more than 800 miles of its course, above the Yellala Falls, the river looks more like a long winding lake than anything else, forming a magnificent channel for navigation. Above the upper cataract, again, about the equator, many other long reaches are capable of navigation, while the affluents will afford over 1,200 miles, and perhaps much more. Some idea of the increasing magnitude of the river below Nyangwe may be obtained from Stanley's statement that at Nyangwe the volume is 124,000 cubic feet per second, while Behm's calculation on the basis of Tuckey's trustworthy observations makes its volume at the mouth to be $1,800,000$ cubic feet per second. Poor Tuckey comes in for a share of Stanley's castigation, because, according to Stanley, the former mistook the number of stages of the Yellala Rapids; even if Tuckey was a little out in his counting, which we doubt, he will still be found to have been, all circumstances considered, an accurate observer. Many points, also, in connection with the map, show how true was Livingstone's geographical instinct, and how near the truth his inferences came from the information obtained from the Arabs and natives. Stanley is probably right in conjecturing that the Aruwimi, coming from the north-east, and joining the Livingstone a little north of the equator, is the Welle, and that the Ikelemba is the lower course of the Kasai. The water of the latter is of the colour of tea, and does not thoroughly mingle with the main stream until after I 30 miles below the confluence. The banks of the great river are thickly populated by what appear to be industrious people living in extensive and well laid out towns, and naturally jealous of intruders. The three most powerful tribes on the middle and lower rivers are the Wa-Mangala, the Warunga, and the Wyanzi.

The Livingstone, Mr. Stanley found, is subject to periodical rises mainly owing to the rains, and varying from eight to fifty feet. The entire length of the Livingstone Mir. Stanley calculates at 2,900 miles, and its basin at 860,000 square miles. The extreme sources of the Bemba Lake, from which the Luapula flows, are in $33^{\circ} \mathrm{E}$. long. Lake Bemba, or Bangweolo, Stanley states-and there appears to be good ground for the belief -is the residuum of an enormous lake that in very ancient times must have occupied an area of 500,000 square miles, "until by some great convulsion the western maritime mountain chain was riven asunder, and the Livingstone began to roar through the fracture." As to the "great convulsion" and the "fracture," geologists may be able to decide when they are in possession of full information as to $\mathrm{Mr}$. Stanley's observations. Nyangwe, Mr. Stanley informs us, is in $4^{\circ} 16^{\prime} \mathrm{S}$., and $26^{\circ} 5^{\prime} \mathrm{E}$.; but by an unaccountable mistake in another place he gives the latitude as $26^{\circ}$ $15^{\prime} 45^{\prime \prime}$, and that, too, while pointing out, in his peculiar way, a slight mistake in the position on Stanford's map of
1874. The position then was perfectly correct according to the data, and in the latest editions the position is exactly as Stanley gives it.

Mr. Stanley insists on the importance of the river as a commercial highway, the country traversed by it being abundantly rich in products that would find a ready market in Europe. Naturally, on Monday night, Africa was the burden of the president's address at the opening of the Geographical Society. Sir Rutherford Alcock insisted that it now remained with the merchant, aided if need be by Government, to open up Africa still further. Indeed the country is now being attacked by national and private expeditions on all sides, and if a basis for minute exploration were formed by trading stations under government sanction and regulation, along the Livingstone, our knowledge of the country would grow rapidly, and the benefits to commerce would be incalculable. Only, however, could the natives have fair play by governmental regulation of private enterprise. There is no danger of extinction for the native African, and it would be both prudent and just to protect him from the horrible cruelties at which Mr. Stanley hints in the conclusion of his letter.

It is worth noticing that in the map the Lukuga runs boldly from Lake Tanganyika and joins the Lualaba, and the source of the Alexandra Nile is brought to near $4^{\circ}$ south on the east side of the lake.

According to latest intelligence Mr. Stanley is at the Cape wanting to get his followers sent back to Zanzibar. In his letter in yesterday's Telegraph he gives an interesting account of his companion, Frank Pocock, of whom he speaks in the highest terms, and whose death is a real loss to African exploration.

The Daily Nezes Alexandria Correspondent writes (on the 5th) that Signori Gessi and Matteucci have just started from Cairo for Khartum, viâ Assouan, by the Nile, instead of taking the shorter route by the Red Sea to Massowa. They are provided with the newest and most improved scientific instruments, and having promised to keep up constant communication with the Geographical Society at Rome, interesting accourts of their movement and progress will be looked for.

\section{MODERN TORPEDO WARFARE}

TWO elements have contributed to make torpedo warfare what it is : electricity and the new explosive compounds. It is true that in the Whitehead or fish torpedo recourse is had only to the latter of these, but it is the sole material exception, and all the mischief effected by this branch of marine warfare has been, so far, the result of electric torpedoes. Both on the Danube and in the last American war, when no less than twenty-five ships were sunk by the Confederates, the electric torpedo has worked extensive injury, and it is no wonder therefore that a keen interest should be taken in all that pertains to so novel and destructive a method of killing and wounding.

We have called the torpedo a novel weapon, and the instruments that go by the name to-day undoubtedly are so. At the time of the Crimean war, we had to do with torpedoes of a kind; nay, even so far back as the beginning of the seventeenth century, floating charges, called petards, were employed, but these were of too insignificant a nature to merit attention. The "infernal machines" strewn in the Baltic by the Russians twenty years ago were small canisters of powder containing by way of igniting arrangement a mixture of chlorate of potash and sugar, together with a glass bulb with sulphuric acid; and the latter, escaping from its envelope when this was broken by a shock or collision, brought about an immediate explosion. These mechanical torpedoes had two disadvantages; the igniting arrangement was of such a character that it could be set in action just as well by friend as by foe, and the explosion of the gun- 
powder was insufficient to effect any material injury. All this has been remedied. Electricity is nowadays employed as the igniting agent, and those terribly violent explosives, gun-cotton and dynamite, replace the comparatively innocuous gunpowder.

Electric torpedoes may be broadly divided into two classes: offensive and defensive torpedoes. The latter are employed for the protection of harbours, channels, and roadsteads ; the former, in the shape of drifting or spartorpedoes, are carried to the attack in small swift-sailing steam-launches. In this country we are favourably disposed to the employment of compressed gun-cotton in our machines, while on the Continent they seem to entertain a predilection for nitroglycerine, or rather dynamite. Both compounds are what chemists term nitro-compounds, in contradistinction to gunpowder, which comes under the class of nitrate-compounds, and appear to exercise an explosive force of almost similar violence, measuring the substances weight for weight. Compressed gun-cotton, we need hardly say, is cotton yarn acted upon by nitric and sulphuric acids and then pulped and washed, so that the result is a finely-divided mass which may be made to assume any shape or form. As a rule the material is pressed into cakes of disc-like form, which weigh from a few ounces to a pound, and while still wet the slabs are stored away in the magazines. In this moist condition

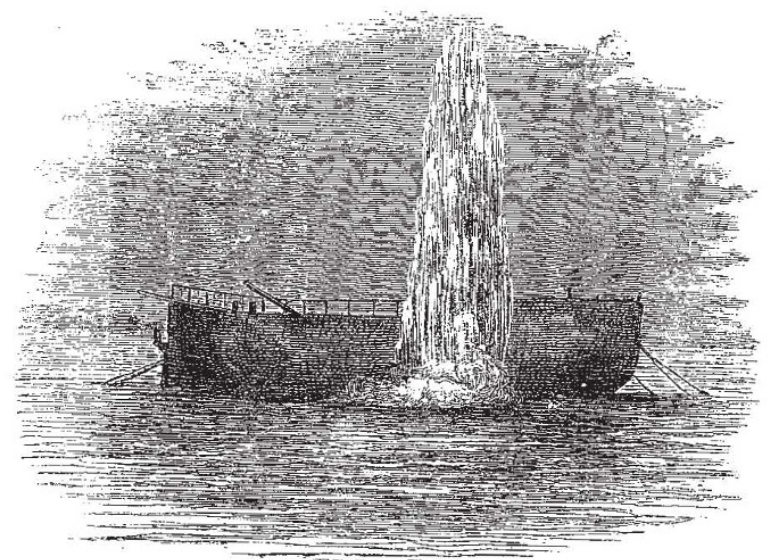

Fig. x.-Fish Torpedo exploding against a ship.

the compressed pulp is not only non-explosive, but actually non-inflammable, except one possesses the key to its detonation. This is nothing more than a dry cake of the same material, or as the latter is termed in military parlance, a "primer," which on being detonated by a few grains of fulminate, brings about the explosion of any wet gun-cotton in its immediate neighbourhood. Thus if simply a net is filled with gun-cotton slabs and thrown into the sea, the whole charge may be ignited by a primer contained in a waterproof bag having an electric fuze and wire attached. The possibility of communicating explosion in this way by vibration instead of by spark or flame is, too, as we shall presently see, the germ of a system of counter-mining, or torpedo annihilation, which bids fair to develop into a particularly effective means of defence against these terrible machines. Dynamite is similarly exploded to gun-cotton. The active principle in this case is nitro-glycerine, or, if you will, liquid gun-cotton, prepared by simply allowing glycerine to fall drop by drop into nitric acid. As a solid is usually more convenient to handle than a liquid, the use of pure nitro-glycerine has given way to dynamite, which may be described as siliceous earth impregnated with the explosive fluid.

Dynamite and gun-cotton explode with something like four or five times the force of gunpowder, and for this reason a very destructive charge may be confined within a comparatively small space. Moreover they are peculiarly adapted to submarine mines, since nitroglycerine is no more affected by water than gun-cotton; and the old adage "to keep your powder dry" does not apply to either of them. In the case of moored torpedoes which are connected with batteries to the shore or carry their own means of generating electricity, as in the Herz topedo of our German cousins, there is no limit to size, and machines containing as much as 500 lbs. of gun-cotton have, in fact, been constructed; but for a spar-torpedo, or in other words one which is thrust under an enemy's keel by means of a thirty-foot pole projecting from the prow of a launch, the charge must be considerably smaller, and for two reasons. A great weight at the end of such a lever could not be properly manipulated, while the explosion, if the charge were a very large one, would destroy both the attacking and attacked. A big moored torpedo of 500 lbs. has been found, when sunk in thirty or forty feet of water, to be fatal to a strong ironclad if the latter happens to be within this distance of the source of explosion ; or, in other words, a cush:on of water forty feet in thickness is not sufficient to secure the immunity of such a vessel. What would happen if this terrible volcano were to erupt-if we may use the wordin contact with the sides of an armoured ship, must be left to the imagination; but despite Mr. Ward Hunt's opinion to the contrary, we do not think it would require

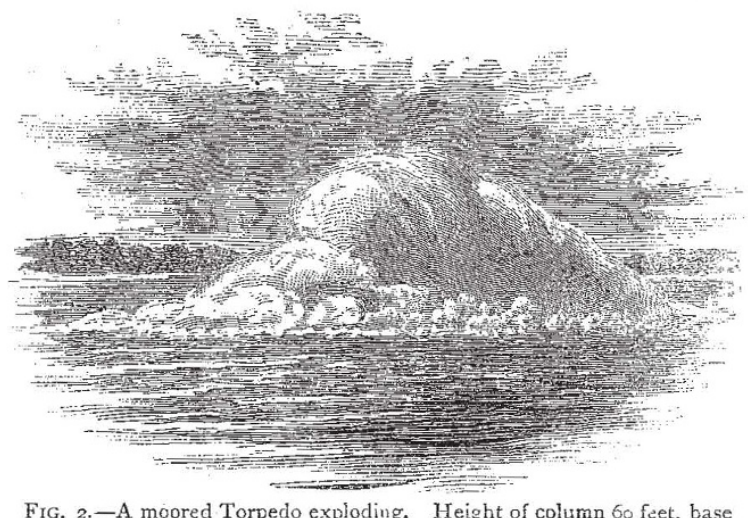
220 feet.

three such torpedoes successfully exploded, to bring our boasted Inflexible to grief. And in this opinion our readers, we suspect, will fully agree, when we inform them that a heavy torpedo like this throws up a cone of water sixty feet in height, with a diameter at its base of no less than 220 feet. Such an heaving of waters, if it did not break the back of an ironclad, as there is every reason to suppose it would, must inevitably capsize her without more ado. But it is, of course, only on very rare occasions that such a monster torpedo could be brought to bear, and in all cases of attack the charge must needs be considerably less. The smaller Whitehead torpedoes, which, as our readers know very well, are narrow cigarshaped weapons, that move through the water by the agency of compressed air, do not in all probability carry more than a $40 \mathrm{ib}$. or $50 \mathrm{lb}$. charge in the head, while a spar or drift torpedo of Ioo lbs. is already as large as would be convenient to handle. At the same time either of these would quite suffice to fracture an iron plate several inches in thickness, and therefore be fatal, probably, to any ironclad afloat, supposing there was no water-cushion between the craft and the torpedo. We have no definite information respecting the size or weight of the torpedoes which sank the Turkish monitor in the Matchin Canal, but as the expedition was hastily arranged and organised, the charges were, no doubt, not very large.

The fish torpedo is a rare example of a complicated apparatus coming into practical use, and its elaborate 
construction and fine workmanship may be imagined when the reader is informed that the machines cost $500 l$. a piece to manufacture. The long tube is divided into three compartments: the head, which contains the explosive charge, the reservoir, in which the compressed air is stored, and the machinery by means of which the stored-up energy is converted into a propelling force. The air is compressed to the extent of 600 Ibs. on the square inch, and to bring about this result an exceedingly powerful air-pump is necessary, which forms an additional item of expense in the case of this torpedo. The latter when properly charged will do a journey of a mile, or mile and a half, under water, the first 1,000 yards being got over at a rate of no less than twenty miles an hour, and if unaffected by tide or current, the machine will proceed in a perfectly straight direction. It floats at any distance under water that may be desirable, but is usually made sufficiently buoyant to swim at eight feet from the surface; it explodes on striking any object, but the machine is so contrived that if it fails to strike, then it floats to the surface, and a trigger guard renders the fish at the same time innocuous, and permits of its recapture without risk. Ingenious as the little creature is, there has been, we repeat, no authenticated employment of it during the present war.

On the Danube the spar-torpedo"alone seems to have been used against Turkish monitors." As in the case of the Thornycroft launch, of which we are to have a flotilla of thirty in the British navy, the torpedo is projected at the end of a spar, and is ignited either by concussion or by electricity. The Turkish ironclad at Matchin was the victim of two torpedoes of this class, the first of which, we are told, was ignited by the crew of the launch by electricity, and the other on concussion with the vessel attacked. These Russian torpedoes are said to be innocuous at a distance of ten feet from the seat of explosion, and hence those in the launch do not suffer much except from the water that is thrown into the air. From the fact that small batteries in the boat are used to fire the charges, we may safely conclude that their explosion is brought about by a platinum wire fuze, which, together with a few grains of fulminate, would determine the detonation of dynamite or gun-cotton. Each launch is provided with a pair of these spar torpedoes, carried, when not in action, on each side, running the length of the boat, and only on making an attack is one or other projected at the bow, the torpedoist being stationed behind a shield, or under an iron screen, where he can make his observations tolerably free from danger.

In the case of moored torpedoes depending for their ignition upon electricity, many points of scientific interest have recently been brought to light. Some experiments undertaken in Denmark two or three years ago showed most conclusively that dynamite torpedoes cannot be placed close together without incurring the danger of one charge bringing about the explosion of others. A dynamite torpedo of 150 lbs. ignited in ten feet of water, was found capable of exploding other charges at a distance of 300 feet by the mere vibration imparted to the water; so that in constructing coast defences with dynamite torpedoes it is absolutely necessary to keep them far apart from one another. Another point was also noted. A current of electricity, if it emanates from a powerful frictional electric machine, traversing one of a bundle of wires, will induce a current in the other wires, and thus bring about the explosion of torpedoes other than that which the operator on shore desires to ignite. It is these facts particularly which have led to the development of a system of counter-attack and have enabled our sailors to devise a means of defending themselves from the terrible sea-monsters. Both dynamite and gun-cotton are peculiarly sensitive to vibration-indeed their detonation, as we have seen, is brought about by no other cause-and hence a captain of a man-of-war by exploding counter- mines in his vicinity may soon get rid of any lurking torpedoes lying in wait for him, at any rate if they contain a nitro-glycerine compound, and so speedily clear a way for his ship.

This is certainly subject for " congratulation, for it seemed at one time as if the poor sailor was absolutely defenceless against these submarine abominations. $\bar{A}$ crinoline of spars and wire rope may be employed to catch the fish torpedo and explode the vermin harmlessly in its toils, provided the ingenious brute is not a very large one, and the net is at some distance from the ship; but heavy moored torpedoes have been hitherto considered too dangerous to approach, so that marine countermining must prove invaluable. The spar or drifting torpedo cannot be dealt with by nets or booms alone, and in this case the only plan would seem to be to meet attack with attack and beat off launches with other small boats, That all ironclads in time of war will have to be surrounded by lesser craft as a protection is a matter that we may now take for granted, as also that such vessels must be provided with some powerful means of illumination-the electric light, for instance-to prevent swift low-lying torpedo launches from approaching unperceived at night time.

Special schools of instruction for acquainting officers with the science of electricity and explosives have for some time past been established, and there is indeed scarcely a naval power which has not paid attention to submarine warfare ; consequently we may expect to see future battles upon the sea carried on just as much under water as above it. In this country we have a torpedo school on board H.M.S. Vernon at Portsmouth, while at the Royal Naval College at Greenwich instruction in the experimental sciences now forms one of the most important items in the curriculum. France has its naval torpedo school at Boyardville, where both officers and seamen are made acquainted with the principles of submarine warfare. Germany, as all the world knows, practised torpedo warfare to such good purpose seven years ago that the magnificent fleet of the French never once ventured to visit the coast of the Fatherland. Both at Kiel and at Wilhelms. haven are to be found torpedo depôts and a well-organised staff of instructors. Lastly the news comes to us from Russia that the Czar has sanctioned the organisation of a distinct torpedo service, and two depôts and instructional schools are to be formed at Kertch and Cronstadt, whence torpedo appliances are to be issued for the defence of the Baltic and the Black Sea.

\section{NOTES}

Mr. DARWIN will receive the honorary degree of LL.D. at Cambridge on Saturday next, at 2 P.M., at a congregation specially convened for the purpose. In the evening the annual dinner of the Philosophical Society will take place in the Hall of Clare College, when a brilliant gathering is expected to meet the illustrious visitor, among the non-resident guests being Profs. Huxley, Tyndall, and Parker, and Sir John Lubbock.

THE Postmaster-General of the German Empire is about to have an extensive series of experiments made with a view to the introduction of the telephone into the telegraphic service. Several hundred specimens of the telephonic apparatus manufactured by Siemens and Halske have been ordered.

THE French Ministry had granted a pension to the widow of Leverrier. Unfortunately the lady died, as we mentioned in our last number, before the first monthly instalment became due. It is hoped that a part of the pension will go, against ordinary rules, to the son and daughter of the astronomer.

THE Minister of Public Instruction has been authorised by a 